\title{
Counselors as Advocates: Effects of a Pilot Project Designed to Develop Advocacy Knowledge and Confidence in Trainees
}

\author{
Lisa M. Edwards, PhD \\ Marquette University
}

Kevin A. Tate, Ph.D., LPC
Wellesley College

Jennifer M. Cook, Ph.D., LPC, NCC, ACS

Marquette University

Michelle P. Toigo, M.S.

Marquette University

\author{
Abigail C. Yeomans, M.S., LPC \\ The Family Institute at Northwestern University
}

\begin{abstract}
While there has been increased attention to advocacy within counseling and counseling psychology, it has been noted that trainees generally feel unprepared to engage in advocacy and do not participant $e$ in this type of work to a large extent, even with increased age or professional experience). The qualitative study summarizes the findings of a project within a graduate multicultural counseling course designed to increase trainee knowledge and confidence related to advocacy. This project required students $(N=19)$ to complete individual advocacy projects in the community, with opportunities for self-reflection and evaluation of their progress throughout the semester. Student reflection responses about the effects of this project were analyzed using methods from Grounded Theory by a collaborative research team. This process resulted in a core category of responses that included expanded definitions of advocacy, increased self-confidence regarding advocacy work, obstacles encountered, and reactions to the course assignment. Implications and future directions are discussed.
\end{abstract}

Keywords: Advocacy, Counselor Preparation, Multicultural, Social Justice, Training 


\section{Introduction}

Advocacy can be considered the actions professionals take to promote social justice and enact change on the individual, group, and systemic levels (American Counseling Association [ACA], 2014; Toporek, Lewis, \& Crethar, 2009). Advocacy includes using knowledge and skills related to understanding the impact of cultural and social factors on development, framing client's concerns within systems, becoming aware of clinicians' own biases, and working to remove systemic barriers to clients' well-being (Toporek \& Liu, 2001). Several ethical standards and practice guidelines (e.g., ACA, 2014; APA, 2002; Ratts, Singh, Nassar-McMillan, Butler, \& McCullough, 2015) charge counselors and psychologists to engage in advocacy, yet it has been noted that trainees generally feel unprepared to engage in advocacy (Steele, 2008). Furthermore, trainees do not participate in this type of work to a large extent, even with increased age or professional experience (Nilsson \& Schmidt, 2005). Additionally, there is a dearth of research about how to teach counseling trainees about this topic and how to increase their confidence in their ability to conduct advocacy in the future (Bemak \& Chung, 2011; Motulsky, Gere, Saleem \& Tranthem, 2014; Murray, Pope \& Rowell, 2010). Therefore, the current study was designed to explore the effects of a pilot advocacy project within a multicultural counseling graduate level course aimed to help counseling trainees develop advocacy knowledge and confidence.

In their conceptual article, Bemak and Chung (2011) noted that few training programs move beyond theoretical discussions of the importance of advocacy to action, even though Beer, Spanierman, Greene, and Todd's (2012) research demonstrated that counseling trainees have the desire for more training and advocacy opportunities than what they receive during their training programs. This lack of attention to the practical applications of advocacy training may be due to a limited of studies about how to teach these skills, given that researchers have noted there are few peer-reviewed articles that focus on pedagogical strategies to engage counseling and counseling psychology students in advocacy (Motulsky et al., 2014; Murray et al., 2010). To date, the majority of empirically investigated teaching strategies related to social justice or advocacy have focused on building students' overall multicultural competence, often through immersion experiences or service learning (e.g., Hippolito-Delgado, Cook, Avrus, \& Bonham, 2011; Ishii, Gilbride, \& Stensrud, 2009; Murray et al., 2010), but not specific advocacy competence. Questions remain about how to best teach students about advocacy knowledge specifically, and how to increase students' confidence to engage in advocacy efforts.

\section{Engaging Students and Navigating Obstacles in Advocacy}

Few studies have explored counseling students' interest in participating in advocacy (Beer, 2012; Caldwell \& Vera, 2010; Nilsson \& Schmidt, 2005). In one study of counseling students who engaged in advocacy, Nilsson and Schmidt (2005) found that high interest in politics and high desire to engage in advocacy predicted student engagement. In a more recent study of critical incidents in graduate social justice training, Caldwell and Vera (2010) discovered that exposure to injustice and the influence of significant persons were critical incidents that led to advocacy. Additionally, in a mixed method study, Beer and colleagues (2012) reported that a sense of personal spirituality (e.g., inner strength, compassion) and a supportive training environment predicted a commitment to social justice among counseling psychology trainees. Although more research is needed to understand better what might increase counseling trainees' likelihood to engage in advocacy, these findings suggest that exposure to injustice and political issues, as well as role modeling within the training environment, should be considered in pedagogical approaches.

In addition to factors that might promote advocacy engagement for counseling students, barriers exist that may impede students' interest and confidence within this area. Nilsson and Schmitt (2005) noted that trainees struggle to translate theory to action and therefore do not engage in advocacy, while 
Heinowitz and colleagues (2012) found that the primary barriers for students were uncertainty, unawareness, and lack of knowledge about public policy issues. A way to address obstacles to lack of preparation and uncertainty is to provide the opportunity to engage in new behaviors and experience a certain degree of mastery, such that confidence can be increased. Further, Decker, Manis, and Paylo (2015) suggested social justice advocacy must be integrated into counselor identity early and often in counselor training programs, which may increase students' identities as advocates as part of their counselor identity. It is within this context of enhancing knowledge and promoting confidence that the current advocacy project was designed. Specifically, this project included several components aimed at increasing awareness and confidence in advocacy for counseling trainees.

\section{Pedagogical Strategies for Teaching Advocacy}

Numerous scholars have recommended self-reflection activities to raise students' multicultural awareness and knowledge, as well as advocacy (e.g., Brady-Amoon, Makhija, Dixit, \& Dator, 2012; Decker, Manis \& Paylo, 2015; DeRicco \& Sciarra, 2005; Motulsky et al., 2014). Burnes and Singh (2010) suggested the use of student reflection journals in conjunction with course materials to increase social justice training in general. Journals can include instructor-initiated prompts, unguided reflections, or reflections about critical incidents. For example, Collins, Arthur, and Brown (2013) found that student reflections on critical incidents related to multicultural and social justice competency stimulated Canadian counseling students' self-awareness and helped students connect theory to practice.

In addition to providing a structured method for self-reflection to promote social justice competence in general, authors have suggested the importance of engaging in community learning outside the classroom as well (Ali, Liu, Mahmood, \& Arguello, 2008; Bemak \& Chung, 2011; Decker et al., 2015). Experiences can include those the instructor creates (e.g., service learning) or those that students initiate (e.g., immersion experiences). While community engagement has been integrated into multicultural courses for decades, the focus on these experiences has been related to broad multicultural exposure. In the only empirical study that focused on community learning for the specific purpose of developing advocacy skills, Murray et al. (2010) assigned a group service learning experience to all counseling students that required promoting a public policy event regarding sexual health for the community. In their qualitative analysis of students' experiences working together on the project, the authors found that despite the challenges students faced, they gained broader context and application skills about real-world concerns, policy knowledge, and awareness, as well as advocacy skills and competence. Additionally, Murray et al., 2010 found that most students reported increased classroom dialogue. Thus, the combination of an outside project and classroom learning proved helpful for developing students' advocacy abilities.

While the findings of the Murray et al. (2010) study suggested the assignment was successful in helping to increase trainees' advocacy competencies, the authors provided potential ways to improve the project. For example, they noted that students were not provided with a theoretical framework for advocacy work (e.g., ACA Advocacy Competencies; Lewis, Arnold, House \& Toporek,2003; ACA Multicultural and Social Justice Counseling Competencies; Ratts, Singh, Nassar-McMillan, Butler, \& McCullough, 2015), which might have helped provide context and knowledge in this area. Also, the project was designed for group service learning and students did not choose the topic of their project, a modification that might result in increased engagement or motivation. The current study, therefore, was designed to expand upon previous research by exploring the effects of a course-based, individual advocacy project assignment focused on developing students' advocacy knowledge and confidence. The overarching research question for this qualitative study was: What are the effects of a course-based advocacy assignment on counseling trainees' advocacy knowledge and confidence? 


\section{Method}

Given our interest in developing an explanatory model to understand the effects of the advocacy assignment on trainees, we utilized qualitative research methods based on Grounded Theory (e.g., Corbin \& Strauss, 2014). Grounded Theory allows for structured, systematic data collection and analysis, as well as the inductive derivation of a core category to describe the phenomenon of inquiry. This methodology has been noted for its adaptability, with approaches ranging from post-positivist (e.g., using precise forms of inquiry to understand absolute truth but acknowledging that reality can only be approximated) to post-structural (e.g., an anti-paradigm that often produces alternative forms of inquiry and/or rejects traditional research (Fassinger, 2005; Hatch, 2002; Levers, 2013). The paradigm for the current project can best be conceptualized as post-positivist, given the project's use of structured coding and categorization to capture participants' lived experiences.

\section{Participants and Data Generation}

The data for this study were generated by students enrolled in a masters-level multicultural counseling course in a mid-sized, private, non-profit university in the Midwest. The course was comprised of 19 students (12 females and 7 males) who were pursuing clinical mental health and school counseling degrees. All but four of the nineteen students identified as White; the remainder identified as African American (two) and mixed race (two). All the students were in their $2^{\text {nd }}$ and final year in the master's program.

At the beginning of the course, students were presented with a required assignment to develop an individual advocacy project. Students engaged in a sequential reflection process at three points: before beginning the project, during the planning stage, and after project implementation. At each step, students completed written entries in response to specific prompts (see Appendix). The first prompt occurred on the first day of class and was included on an information form designed to ask students to provide their name, current courses, and the name of internship site. In addition to this basic information, students were asked to describe what advocacy meant to them and describe their current level of confidence in doing counseling advocacy. Soon after completing this information form, students read and discussed readings about advocacy during class (e.g., Lewis et al., 2003; Toporek et al., 2009) to lay the theoretical foundation for the project and advocacy in general.

Next, within the first month of enrollment in the course, students were asked to identify a potential issue at their clinical internship site or in the community that could be a target for advocacy. The problems and projects they identified varied widely. Some examples included creating a referral list of Spanish-speaking resources in the community for a clinic in which no such directory was available, and designing a bulletin board with bus lines and transportation information for clients at a community mental health center where the majority of clients took public transportation, but there were no resources about transportation.

Table 1 describes how students completed a planning form within the first month of class, which consisted of several questions designed to help them refine their rationale for choosing the advocacy concern, potential solutions to the issue, and next steps for selecting a project. During at least two class sessions, time was devoted to discussing ideas with peers before the planning form was due to the instructor. Students received feedback about their ideas from the instructor, and they were given final approval soon after submitting their planning form. 


\section{Table 1}

\section{Question Prompts for Students' Initial, Planning, and Final Written Reflections}

1. Initial Question (I)

a. What does counseling advocacy mean to you?

b. How confident do you feel that you can engage in counseling advocacy?

2. Project Planning $(\mathrm{P})$

a. How do you feel about the problem-concern you identified?

b. How do you feel about this advocacy project and the next steps you are hoping to take?

c. Other comments and reactions to this assignment

d. Other comments and reactions about social justice advocacy

3. Final Form (F)

a. How do you feel about the advocacy project you developed?

b. What were the obstacles you encountered when developing this project, and how did you address them?

c. What did you think about this assignment and its relevance in a course like Multicultural Counseling?

d. What does counseling advocacy mean to you?

e. How confident do you feel that you can engage in advocacy in your counseling work, and why?

f. Other comments and suggestions

After approval, students worked independently until the end of the semester (i.e., around ten weeks) to complete their projects. The instructor provided feedback and support with problem-solving as needed. In most cases, the original project was completed, but in some cases, slight modifications had to be made (e.g., develop a brochure and group outline rather than run an actual group). At the end of the semester, students gave a brief presentation of their project to the class and provided a handout that described the project. Also, they completed a final response paper (see Appendix A) about the entire assignment (e.g., relevance to the course and ways to improve) and their advocacy project experience (e.g., obstacles encountered, the meaning of advocacy, level of confidence in conducting advocacy). Data for each participant, across all three entries, ranged from between 3-6 pages of double-spaced text. Initially, these entries were not intended for research purposes, yet the content generated seemed to have the potential for novel findings about counselor-in-training advocacy competency development. As such, we applied for and received IRB approval one year later to analyze these data that were obtained through standard educational practices and settings.

\section{Data Analysis Procedures}

The students' reflection responses were qualitatively analyzed by the research team using methods based on Grounded Theory (e.g., Auerbach \& Silverstein, 2003; Corbin \& Strauss, 2014).

Research team. The primary research team consisted of two faculty members (a 40-year-old who identified as a biracial female, and a 38-year-old who identified as a White male) and two master's students (a 24 year-old who identified as an Iranian American female, and a 23 year-old who identified as Caucasian) from the previously described counseling program. The two faculty members had considerable research and professional experience in the areas of multiculturalism and advocacy, and one member was the instructor of the course. Both had experience completing qualitative studies. The two student members had only received a brief introduction to advocacy and qualitative research in their Master's counseling courses, though they had each been exposed to advocacy in their 
undergraduate universities and had experiences doing advocacy in the community. The data from participants were from a cohort that had graduated two years before the student team members' cohort, and all data were de-identified.

Ensuring trustworthiness. The team spent several weeks discussing the research project, reviewing relevant articles about advocacy (e.g., Toporek et al., 2009) and data analytic methods (e.g., Auerbach \& Silverstein, 2003). To minimize projecting personal experiences while maximizing team expertise (e.g., reflexivity and justifiability; Auerbach \& Silverstein, 2003), the team members discussed their potential biases before beginning analysis. Some of the typical expectations and prejudices the research team members shared were that participants would have a low sense of confidence about advocacy due to the belief that advocacy must involve systemic, substantial changes, and that involvement in the class project would increase confidence and comfort with advocacy. Additionally, members expected that students might have vague definitions of advocacy at the beginning of the semester, and they would become more precise in their understanding of what advocacy could be after completing their project. Throughout the project development and analysis process, an audit trail (via detailed notes on meeting agendas) also was developed. The trail included the following: over 140 pages of notes about methodological decisions (e.g., keep the category of obstacles distinct from suggestions of how to improve the assignment), insights and reflections (e.g., participants began using the language of the advocacy competencies more), and data analysis procedures (e.g., begin coding responses for one question individually and then compare as a team) from all team members, which served to substantiate trustworthiness (Carcary, 2009; Rodgers \& Cowles, 1993).

Data analysis. Research team members first individually reviewed and coded/labeled all participants' data line-by-line. After this independent open coding phase (Corbin \& Strauss, 2014), the team met to discuss and compare their concept lists, to verify that each important phenomenon in the data had been coded, and to collapse concepts with equivalent meanings. At the end of the open coding phase, an initial list of 195 meaning units was generated. Team members then began the process of grouping concepts into broader categories based on their interrelatedness. The initial list of categories was reviewed by the team to assess the fit of each meaning unit into the initial category and to ensure that all relevant pieces of data had been coded and sorted. The result of this phase was the creation of a master category list of 24 categories.

The process of axial coding (Corbin \& Strauss, 2014) involved the clarification of the relationships between each category and the participants' experiences, through a process of constant comparison. This process led to the emergence of four key categories (e.g., definitions of advocacy, increased student confidence, obstacles to engaging in advocacy, and reactions to the course assignment). These initial findings were sent to an external auditor (a 36-year-old faculty member who identifies as a White female) with significant experience in advocacy and social justice training, to ensure the dependability of our findings. The auditor was asked to provide perspectives on category titles and the fit of the data within each category. The auditor's feedback included notes about quotes that did not seem to fit under categories, suggestions for how to clarify headings, and general thoughts about the emerging data. The team met to discuss the feedback provided by the auditor and made slight modifications to the wording of the findings. For example, definitions of advocacy were changed to expanded definitions of advocacy.

The final phase, selective coding involved extensive discussions about the role of each category in participants' experiences and its relationship to other categories (Corbin \& Strauss, 2014). The following core category emerged from which participants' experiences were understood and explained: Engaging in individual advocacy projects in the community allowed counseling trainees to have expanded 
definitions of advocacy and increased confidence about how to conduct advocacy and navigate obstacles related to advocacy work. It should be noted that the first three categories (expanded definitions of advocacy, increased student confidence, and barriers to engaging in advocacy) primarily informed the core category, while the final category (suggestions for improvement of the advocacy project) was less prominent.

\section{Results}

In the following section, we describe the primary four categories that emerged from our data analysis. Participant quotes are provided to illustrate the themes. Using a system similar to one used by Richie et al. (1997) and Pope-Davis et al. (2002), we discuss the responses according to the following cut-offs: a) The words "generally, most, many, the majority, usually" and "typically" indicate the characteristic response of a majority (14 or more) of the participants; b) The words "some, several," and "a number of" indicate responses from 7-12 participants; and c) a few indicates responses from six or fewer participants. Though the last category ("suggestions for improvement of the advocacy project") was not as closely tied to the core category, we still summarize the findings of this category because it had specific suggestions for instructors.

\section{Expanded Definitions of Advocacy}

Students were asked what advocacy meant to them at both the beginning and end of the assignment. In the beginning, before students had started their projects, the majority indicated that advocacy meant supporting a client, for example, "using the position I am in during the counseling relationship to better serve my client." Additionally, students discussed counseling advocacy to make changes to unjust systems and situations. As one student indicated: "counseling advocacy means identifying what social change must occur or would ultimately be beneficial to the clients I am working with."

Many students referred to macro-level changes in their definitions of advocacy as demonstrated by the following response: "Policy changing, perception-altering in the immediate community and the community at large." Finally, a few students responded with confusion as to clear meaning of counseling advocacy, noting, for example: "I feel like this term is thrown around daily but I still believe that I truly don't understand what advocacy means."

After the project was completed, students reflected again on what counseling advocacy meant to them. Their responses revealed an expansion in their previous definitions. For example, the most common responses stated that advocacy was important at both macro and micro levels, and included working with clients in addition to on behalf of clients. As one student noted: "Advocacy shows a client that you are willing to act for and with them, and that can mean a lot to clients who need support from others before they can support themselves."

Also, many students indicated that they now viewed advocacy as a professional responsibility, particularly given their positions of privilege. For example, one student shared: "In my opinion, from what I have learned and experienced thus far, counseling advocacy means fighting for a cause that you can influence due to your current professional position." Another student noted: "My role is to be the connection to knowledge and opportunity that they may have never experienced." Through both increased advocacy knowledge and experience, students could provide a more expansive advocacy definition after they completed their projects than before they began. 


\section{Increased Student Confidence to Engage in Advocacy}

Students were asked to reflect on their confidence in engaging in advocacy at both the beginning and end of their projects. Confidence ratings were categorized by the team as low, fairly confident, confident, and very confident, as well as uncertain. The team established these confidence ratings using the descriptors (e.g., fairly confident) that participants used, and in some cases with similar descriptors (e.g., "I do not feel very confident" was categorized as "low"). In the initial stages of the project, most students expressed feeling "fairly confident" that they could engage in counseling advocacy, believing that more experience engaging in advocacy work would increase their confidence. As one student stated: "I imagine through this classroom experience that I will become better educated and subsequently more confident."

Other students mentioned anxiety about finding the time to do advocacy work and/or that they needed to know more about the community connections and resources available:

I am somewhat confident. I would need to know more/research what I advocate for. Know community connections/organizations, and have enough time." Furthermore, some students said they felt more confident at the micro level of advocacy work than at the macro level. As one student described: "I feel like it's too big right now. That all I am capable of is smaller. For example, I met a politician and will vote for her as advocacy for this field, but I'm not making waves.

When asked to reflect on their confidence level at the end of the project, all but two students indicated feeling confident or very confident at the end of this project. The students who were very confident explained that they now knew advocacy could be done in multiple ways (i.e., not just at the macro level), and they were now even more motivated to create change in the field due to this awareness. For example, one student stated:

I now see that advocacy does not have to be some long, drawn-out process that takes a long time and many resources, but rather can be as simple as helping a client get the strength to stand up for themselves." Another student reported: "Now that I have completed a major project in advocacy work, I believe that my training through the program has also prepared me to engage in such work wherever I end up after graduation.

Students indicated that after having engaged in advocacy work, their confidence levels increased because they had seen how advocacy goals could be implemented. As one student noted:

Before this assignment, I would have rated my confidence in advocacy with my counseling work as low. I was not sure how to serve as an advocate, especially as an internship student. However, after working through this project I feel proud of my work and understand the steps to take in the future.

Another student shared: "It made the previously abstract idea of advocacy a tangible thing that I now feel more comfortable using in the future." Throughout the project, almost all students' confidence to engage in advocacy increased due to expanded understanding about advocacy, especially learning the multiple ways in which they could make change. 


\section{Identification of Obstacles to Advocacy}

Participants were asked to identify the obstacles they encountered while completing their advocacy project, as well as the strategies they used to address them. Students noted that while they were initially excited to design an advocacy project, they experienced hesitations and questions about implementation in the middle of the project/semester. For example, some students who were planning educational workshops noted a hesitancy to be an expert on a topic:

I am nervous and excited. ... I worry about my fears of public speaking, especially surrounded by people with equal or greater education and experience than myself." Also, some students admitted they had some confusion about the best way to implement the project, and several indicated that they needed more readings and resources to gain clarity. Finally, a few students worried that their projects were too small or they might not have enough time to effectively implement their project.

Participants described several specific obstacles as well. The most frequently occurring obstacle was scheduling, which included challenges related to finding time to develop their project plans, as well as finding time to implement the project. Students shared that to cope with the scheduling-related obstacles, they had to be flexible and accommodate to agency and staff members' schedules and the setting. One student who wanted to implement a specific group within her internship site noted:

I was able to compromise by working together with the other staff members. The experience also gave me a good lesson in that advocacy does not always have to be done alone, and can often be more beneficial when done with others.

Another student reported a similar sentiment: "I had to make sure I was not interfering with any of these groups. To address this, I spoke with all of the staff in the partial program/intensive outpatient program, and finally found times that were not interfering with specific groups."

Another common challenge for students was managing the scope of the project (i.e., developing a plan that was reasonable given time and goal parameters). When faced with this challenge, students either sought support from staff or came to terms with the fact that the project could be small and still have an impact on a microsystem level. It appeared that reconciling their significant goals for the project with the realities of intervening at a microsystem level was important for students so they could deal with their obstacles and feel satisfied with the project they developed. As one student who was working on a psychoeducation program for a site stated:

Another obstacle was deciding how much I wanted to accomplish with this project. I did not want to limit myself by only completing a proposal, however at the same time I did not want to go overboard with too much work. I had my eyes set on long-term goals and needed to bring it down to what I could do right now, and save the long-term goals for the future. Therefore, to address this obstacle I made a list of present and future goals. I found this very helpful in selecting a program with a proper balance between the two.

Another student shared, "The main obstacle for me came during the planning process. I thought that this had to be a continuous group. I would have liked to include more recreational activities to build rapport, but my supervisor was fairly certain that a short-term group would be better." Finally, students noted they had obstacles related to details about the project, such as finding reliable information for the activities they designed and finding collaborators to work within the community or onsite. For these 
obstacles, students utilized a wide array of strategies, including giving more time and attention to gathering resources and trying to find an alternative community or staff members who could support their project. One student reported the additional help from support staff was integral in completing the project: "As I received consultation from psychotherapists, social workers, and a psychologist, I became more confident that I selected an appropriate advocacy project."

\section{Suggestions for Improvement of the Advocacy Project Assignment}

When asked about the project's relevance in a multicultural counseling course, most students noted it was practical and empowering, and therefore a good fit for the class. One student stated, "I liked that it allowed me to take a hands-on approach to advocacy and multiculturalism versus just reading and talking about it." Another student reflected that the applied nature of this assignment gave her the knowledge that advocacy is possible and can make a difference:

It helped get our class out in the community, really thinking about how we can create big changes with a little work and effort. I am very glad you assigned this because now I do know it is possible to advocate for our clients, even in small ways, with our busy schedules.

Finally, students noted that being in class and being guided through the project was helpful, even if they did not feel excited about the project at first. One student shared:

I am glad that I have had a chance to do this project in an environment where I could receive support and supervision as a master's student, and it makes me feel more confident that I will be able to do something like this again as a counselor. I think this project makes advocacy work seem a little more actionable.

Another student stated: "At first, I did not think this assignment had very much relevance to the class, however after working throughout the semester and completing this assignment I can see how significant this assignment is to multicultural counseling."

Some students had constructive suggestions for revising this assignment in the future. Most students' feedback revolved around giving more points for the assignment, "due to the time it took to actually do the research and figure out what to do." A few students noted that working in teams, rather than individually, might have been helpful "to put together a few larger scale projects instead of a handful of smaller ones." Finally, a few students suggested that it would be helpful for future classes to be able to look at examples of past projects. In short, students felt that instructor attention to the time commitment, workload, and more examples/structure would be helpful for future students completing this assignment.

\section{Discussion}

This study sought to qualitatively explore the effects of a course-based advocacy project designed to increase knowledge and confidence in advocacy among counseling trainees. Only one other study of a course-based project to promote advocacy was found in the literature (Murray et al., 2010); however, this project involved a group service-learning project, and the authors noted several ways that the effectiveness of their project might be enhanced. The current project expanded on the Murray et al. findings by exploring the effects of a plan that included providing students with a theoretical framework of advocacy (e.g., Lewis et al., 2003) and allowing students to choose their project topics and implement their project individually. Responding to writing prompts remained as a central pedagogical strategy, like Murray and colleagues' study. The core category in the current study --Engaging in individual advocacy 
projects in the community allowed counseling trainees to have expanded definitions of advocacy and increased confidence about how to conduct advocacy and navigate obstacles related to advocacy worksuggested that there were several effects of the course on trainees. These will be discussed below.

\section{Effects of Advocacy Assignment Experience}

The themes that arose from the data in the current study indicated that students experienced developmental shifts with regard to confidence and advocacy knowledge throughout the course of the project. For example, at the end of the semester, students reported an increased sense of confidence in their ability to conduct advocacy, which was a primary goal of the project. Like the findings of the study conducted by Murray et al. (2010), in the current study, experience in engaging in advocacy supported by classroom-based learning bolstered students' confidence to perform advocacy.

In addition, most students experienced an expansion in their definitions of advocacy (i.e., to include micro- and macro- level advocacy work), as well as an understanding that advocacy can take place on behalf of or with clients. Given that advocacy on different levels and working on behalf or with clients are two critical components of the ACA Advocacy Competencies (Lewis et al., 2003), it appears that the current study was useful in helping at least most students understand this definition upon completion of their projects. Moreover, the study demonstrated that providing a theoretical framework for advocacy, as has been recommended by previous authors (Murray et al., 2010), also was essential to facilitate students' learning.

As students' advocacy definitions shifted over the course of the project, so did their thoughts and feelings regarding advocacy. For example, at the beginning of the project, students felt excited yet hesitant to engage in advocacy work and self-reported low confidence. Midway through the project, many students experienced feeling overwhelmed and hesitant as they grappled with the concept of advocacy and how to integrate it into their internship sites. Additionally, they encountered unforeseen obstacles: projects needed to be altered and revised to meet the needs of their clients and to work in a realistic, rather than a theoretical, setting (Bemak \& Chung, 2011; Decker et al., 2015). Students had to ask others for help, tap into their flexibility, and modify their goals to meet the needs of the site where they performed they advocacy project, all of which, it could be argued, can be learned only by engaging in advocacy.

When the project was completed, students reported feeling hopeful that their role as an advocate would make a lasting impression on clients, and they felt confident in their ability to act as advocates. Further, the students' demonstrated ownership of their advocacy role, and many shared they believed it was their professional responsibility to serve as an advocate for their clients. This ownership of the advocacy role was largely absent at the initiation of the project. Consistent with Caldwell and Vera's (2010) findings, it seems that exposure to injustices that client's experience, coupled with working through the multiple steps and layers of the advocacy process, served not only to motivate the students in the current study but also to encourage them to consider themselves as "advocates." Overall, the findings of this study suggested that the project had several positive effects on students and accomplished the project's goals of increasing knowledge and confidence in trainees.

\section{Improvements for Advocacy Assignment}

For any course assignment or project to be successful, it is crucial for educators to consider logistical constraints and obstacles students may face (Murray et al., 2010). For example, instructors should be prepared for how students may understand the scope of the project. In the case of the participants in this study, many believed that to engage successfully in advocacy work, they needed to create large- 
scale projects and thus, large-scale change. This belief proved to be an obstacle in itself and may account for the lack of self- confidence students felt before the project began. Addressing this conflict successfully was critical so students could implement their advocacy project. Students had to reconcile their desire to create major, systemic change, with the reality of being able to develop smaller, clientlevel change. Most students resolved this issue by understanding that smaller-level change impacts clients, while others divided their goals into immediate and long-term categories.

As the planning stage of the project shifted toward the implementation stage, students faced logistical challenges such as scheduling, time constraints, and sparse resources available to them. Students' ability to work with and navigate their organization either facilitated or hindered the success of their project. As students began to recognize the real-world constraints of advocacy work, many sought increased support from supervisors and staff at their internship sites or collaborators in the community, while others completed additional research to find more information for planning and implementation purposes. Most importantly, the primary lesson students reported learning was to adapt their projects based on time restraints, project scope (micro vs. macro), and their client context. Students suggested several changes to improve the project and assignment design.

Overall, they believed the assignment was relevant to the multicultural counseling course and suggested it continue to be assigned to future cohorts. One student suggested project planning should begin earlier in the semester to allow ample time for project implementation and to address any barriers that might arise during implementation. Similarly, some felt more examples of "where to start" would benefit future students, as well as early class conversations about the variety of ways counselors, can act as advocates. Another student recommended that future groups have more time for group processing to receive more input from others throughout the various stages of the project. The instructor agreed with this feedback, adding that group discussion about emerging obstacles might be helpful at several points in the semester. In summary, it is recommended that instructors who integrate such an assignment in their course be aware of the time commitment necessary to complete this project, and be sure to allow sufficient class time for students to plan and share progress with each other throughout the semester.

\section{Limitations and Future Research}

While this study provided initial support for the positive effects of a course-based advocacy project, more research is needed. First, though the methods were derived from Grounded Theory procedures, not all grounded theory strategies were used, which potentially limits the utility of the results. For example, theoretical saturation was not utilized, as all the data were analyzed only upon completion of the project. Furthermore, the prompts for students were quite structured, and responses were brief, which may have limited the richness of the data. Replicating this project in other classes with larger sample size or more in-depth interviews would be beneficial. In addition, because the advocacy assignment was part of a course, the responses were not deidentified and could thus have led to bias in reporting. Students, knowing that they were being evaluated, may have overemphasized their gains in learning or confidence to the instructor.

While participants reported increased confidence in engaging in advocacy, and determination has been viewed as related to performance in some areas (e.g., Stajkovic \& Luthans, 1998), it is still not certain that these participants' confidence would lead to more (or more effective) advocacy work in the future. Indeed, it would be useful to see if learning and engaging in advocacy as a trainee leads to later advocacy as a counselor in the field and how, if at all, this influenced clients and communities. Longitudinal, mixed-method studies might be able to evaluate initial confidence better (e.g., as assessed quantitatively) and how confidence and knowledge change over the course of a project, as well as the 
effects of this training on counselor's later counseling work and client outcomes post-graduation. Finally, further research is needed to understand better how students and professionals navigate the barriers inherent to advocacy work, and what strategies might be most useful to overcome them. Providing information to trainees and counselors about common obstacles and strategies for addressing them may alleviate the hesitations that individuals often share regarding advocacy work (Heinowitz et al., 2012).

\section{Conclusion}

As members of a profession dedicated to ameliorating individual and systemic oppression and injustice, and one that pledges to "do good when we can," educators must endeavor to find ways to train better our students in how to engage in advocacy. Indeed, authors have argued that counselors must meet the role of advocate without hesitation, and training programs are best suited to prepare them for this role (Decker et al., 2015). The current study provided initial findings of the positive effects on knowledge and confidence of a course-based advocacy project. Though this study was only conducted with a small sample and the results should be replicated, it appears that the current plan was successful at bridging the gap between knowledge and application that often leaves many counselors-in-trainings feeling that they need more advocacy training (Beer et al., 2012; Nilsson \& Schmidt, 2005). Specifically, it provides an example of a successful classroom assignment that integrates several pedagogical approaches, including addressing theory, experiential learning, and self-reflection (Decker et al., 2015). It is hoped that future research will continue to investigate training methods that will encourage engagement in advocacy for counseling professionals.

\section{Author Contact Information}

Lisa M. Edwards, PhD is a professor in the Department of Counselor Education and Counseling Psychology at Marquette University in Milwaukee, WI. She is co-director of the Marquette University Latina/o Well-Being Research Initiative. Her research and professional interests include Latina/o psychology, maternal mental health and the intersection of multiculturalism and positive psychology.

Lisa M. Edwards, Department of Counselor Education and Counseling Psychology, Marquette University, Milwaukee, WI. Email: lisa.edwards@marquette.edu; Phone: (414) 288-1433.

\section{References}

Ali, S. R., Liu, W. M., Mahmood, A., \& Arguello, J. (2008). Social justice and applied psychology: Practical ideas for training the next generation of psychologists. Journal for Social Action in Counseling and Psychology, 1, 1-13.

American Counseling Association (2014). Code of ethics. Arlington, VA: Author.

American Psychological Association. (2002). Ethical Principles of Psychologists and Code of Conduct. Washington, DC: Author.

Auerbach, C. F. \& Silverstein, L. B. (2003). Qualitative data. An introduction to coding and analysis. New York: New York University Press.

Beer, A. M., Spanierman, L. B., Greene, J. C., \& Todd, N. R. (2012). Counseling 
psychology trainees' perceptions of training and commitments to social justice. Journal of Counseling Psychology, 59, 120-133. doi:10.1037/a0026325

Bemak, F., \& Chung, R. C. Y. (2011). Applications in social justice counselor training: Classroom without walls. The Journal of Humanistic Counseling, 50, 204-219. doi:10.1002/j.21611939.2011.tb00119.x

Brady-Amoon, P., Makhija, N., Dixit, V., \& Dator, J. (2012). Social justice: Pushing past boundaries in graduate training. Journal for Social Action in Counseling Psychology, 4, 85-98.

Burnes, T. R., \& Singh, A. A. (2010). Integrating social justice training into the practicum experience for psychology trainees: Starting earlier. Training and Education in Professional Psychology, 4, 153-162. doi:10.1037/a0019385

Caldwell, J. C., \& Vera, E. M. (2010). Critical incidents in counseling psychology professionals' and trainees' social justice orientation development. Training and Education in Professional Psychology, 4, 163-176. doi:10.1037/a0019093

Collins, S., Arthur, N., \& Brown, C. (2013). Critical incidents in graduate student development of multicultural and social justice competency. Academic Journal of Interdisciplinary Studies, 2, 105-115. doi: 10.5901/ajis.2013.v2n9p105

Carcary, M. (2009). The research audit trial - Enhancing trustworthiness in qualitative inquiry. The Electronic Journal of Business Research Methods, 7, 11-24.

Corbin, J. \& Strauss, A. (2014). Basics of qualitative research: Techniques and procedures for developing grounded theory (4th ed.). Sage Publications: London.

Decker, K.M., Manis, A.A. \& Paylo, M.J. (2015). Infusing social justice advocacy into counselor education: Strategies and recommendations. The Journal of Counselor Preparation and Supervision, $8(3)$. Retrieved from: http://dx.doi.org/10.7729/83.1092

DeRicco, J. N., \& Sciarra, D. T. (2005). The immersion experience in multicultural counselor training: Confronting covert racism. Journal of Multicultural Counseling and Development, 33, 2-16. doi:10.1002/j.2161-1912.2005.tb00001.x

Fassinger, R. E. (2005). Paradigms, praxis, problems, and promise: Grounded theory in counseling psychology research. Journal of Counseling Psychology, 52, 156-66. doi:10.1037/00220167.52.2.156

Hatch, J.A. (2002). Doing Qualitative Research in Education Settings. Albany, NY: SUNY Press.

Heinowitz, A. E., Brown, K. R., Langsam, L. C., Arcidiacono, S. J., Baker, P. L., Badaan, N. H., Zlatkin, N. I., \& Cash, R. E. (2012). Identifying perceived personal barriers to public policy advocacy within psychology. Professional Psychology: Research and Practice, 43, 372-378. doi:10.1037/a0029161 
Hipolito-Delgado, C., Cook, J. M., Avrus, E. M., \& Bonham, E. J. (2011). Developing counseling students' multicultural competence through the multicultural action project. Counselor Education and Supervision, 50, 402-421. doi: 10.1002/j.1556-6978.2011.tb01924.x

Ishii, H., Gilbride, D., \& Stensrud, R. (2009). Students' internal reactions to a one-week cultural immersion trip: A qualitative analysis of journals. Journal of Multicultural Counseling and Development, 37, 15-27. doi:10.1002/j.2161-1912.2009.tb00088.x

Lewis, J.A., Arnold, M.S., House, R., \& Toporek, R.L. (2003). ACA Advocacy Competencies. Retrieved from https://www.counseling.org/knowledge-center/competencies

Levers, M.D. (2013). Philosophical paradigms, grounded theory, and perspectives on emergence. SAGE Open, 3, 1-6. doi: 10.1177/2158244013517243

Motulsky, S. L., Gere, S. H., Saleem, R., \& Trantham, S. M. (2014). Teaching social justice in counseling psychology. The Counseling Psychologist, 42, 1058-83. doi:0.1177/0011000014553855.

Murray, C. E., Pope, A. L., \& Rowell, P. C. (2010). Promoting counseling students' advocacy competencies through service learning. Journal for Social Action in Counseling and Psychology, 2, 29-47.

Nilsson, J. E., \& Schmidt, C. K. (2005). Social justice advocacy among graduate students in counseling: An initial exploration. Journal of College Student Development, 46, 267-279. doi:10.1253/csd.2005.0030

Pope-Davis, D.B., Toporek, R.L., Ortega-Villalobos, L., Ligiero, D.P., Brittan-Powell, C.S., Liu, W.M., Bashshur, M.R., Codrington, J.N., \& Liang, C.T. (2002). Client perspectives of multicultural counseling competence: A qualitative examination. The Counseling Psychologist, 30, 355-393. doi: $10.1177 / 0011000002303003$

Ratts, M. J., Singh, A. A., Nassar-McMillian, S., Butler, S. K., \& McCullough, J. R. (2015). Multicultural and Social Justice Counseling Competencies. Retrieved from: http://www.multiculturalcounseling.org/index.php?option=com_content\&view=article\&id=205: amcd-endorses-multicultural-and-social-justice-counselingcompetencies\&catid=1:latest\&ltemid=123

Richie, B., Fassinger, R. E., Linn, S. G., Johnson, J., Prosser, J., \& Robinson, S. (1997). Persistence, connection, and passion: A qualitative study of the career development of Highly achieving African American-Black and White women. Journal of Counseling Psychology, 44, 133-148. doi:10.1037/0022-0167.44.2.133

Rodgers, B.L., \& Cowles, K.V. (1993). The qualitative research audit trail: A complex collection of documentation. Research in Nursing \& Health, 16, 219-226. doi: 10.1002/nur.4770160309

Stajkovic, A.D., \& Luthans, F. (1998). Self-efficacy and work-related performance: A meta-analysis. Psychological Bulletin, 124, 240-261. doi: 10.1037/0033-2909.124.2.240 
Steele, J.M. (2008). Preparing counselors to be advocates for social justice: A liberation model. Counselor Education \& Supervision, 48, 74-85. doi:10.1002/j.1556-6978.2008.tb00064.x

Toporek, R. L., Lewis, J.A., Crethar, H.C. (2009). Promoting systemic change through the ACA Advocacy Competencies. Journal of Counseling \& Development, 87, 260-268.

doi:10.1002/j.1556-6678.2009.tb00105.x

Toporek, R.L., \& Liu, W.M. (2001). Advocacy in counseling: Addressing race, class, and gender oppression. In D.B. Pope-Davis \& H.L.K. Coleman (Eds.), The intersection of race, class, and gender in multicultural counseling (pp. 285-413). Thousand Oaks, CA: Sage Publications.

Toporek, R. L., \& McNally, C. J. (2006). Social justice training in counseling psychology: Needs and innovations. In R. L. Toporek, L. H. Gerstein, N. A. Eouad, G. Roysircar, \& T. Israel (Eds.), Handbook for social justice in counseling psychology: Leadership, vision, \& action (pp. 37-43). Thousand Oaks, CA: Sage Publications. 